\title{
Predictive Tool for Closure of Ductus Arteriosus with Pharmacologic or Surgical Treatment in Preterm Infants
}

\author{
TaiXiang Liu ${ }^{1}$ - Zheng Chen ${ }^{1} \cdot$ XiaoLu Ma $^{1} \cdot$ LiPing Shi $^{1}$
}

Received: 17 June 2021 / Accepted: 6 September 2021 / Published online: 12 September 2021

(c) The Author(s), under exclusive licence to Springer Science+Business Media, LLC, part of Springer Nature 2021

\begin{abstract}
To construct a model with the indices obtained by echocardiography to predict whether patent ductus arteriosus (PDA) was required to be treated with pharmacologic treatment or surgical ligation, we performed a prospective observational study, including all neonates with gestational age $\leq 30$ weeks and assessed the hemodynamics of PDA by serial daily echocardiography examination at postnatal age of $0-12 \mathrm{~h}, 24 \mathrm{~h}, 48 \mathrm{~h}$, and $72 \mathrm{~h}$, respectively. The infants were classified in two groups based on whether they were treated with non-steroidal anti-inflammatory drugs (NSAIDs) and/or surgical ligation to close the PDA from the second week after birth. We compared the echocardiographic indices between the two groups and utilized the indices to construct a model to predict which premature infants' PDA requires intervention. The results showed that a total of forty-two preterm infants were enrolled in the study. 15 (35.7\%) preterms were in the intervention group and 27 $(64.3 \%)$ preterms were in the non-intervention group. Compared with the non-intervention group, the intervention group had a higher proportion of left ventricular volume overload and systemic shunt effect. In addition, the combined indicators of PDA size/weight $>3.2 \mathrm{~mm} / \mathrm{kg}$ and LA/Ao $>1.4$ at postnatal age of $72 \mathrm{~h}$ had a highest value to predict whether PDA requires intervention. These findings denoted that serial daily echocardiographic assessment can be useful in predicting whether a PDA will be closed with NSAIDs and/or surgical ligation in preterm infants with gestational age $\leq 30$ weeks.
\end{abstract}

Trial registration Number: IRB No. 2018-IRB-073. Date: 2018/09/21, retrospectively registered.

Keywords Echocardiographic assessment $\cdot$ Hemodynamically significant patent ductus arteriosus $\cdot$ Newborn $\cdot$ Patent ductus arteriosus $\cdot$ Preterm infants

\section{Abbreviations}

AKI Acute kidney injury

ASD Atrial septal defect

BPD Bronchopulmonary dysplasia

COX Inhibitors cyclooxygenase inhibitors

DA Ductus arteriosus

DAo Descending aorta

E:A The ratio of mitral valve E:A

EF Ejection fraction

E:E' The ratio of mitral valve E:E'

EUGR Extrauterine growth retardation

FS Fractional shortening

hs-PDA Hemodynamically significant patent ductus arteriosus

TaiXiang Liu

liu2020@zju.edu.cn

1 Department of NICU, The Children's Hospital, Zhejiang University School of Medicine, National Clinical Research Center for Child Health, Hangzhou, China
IVH Intraventricular hemorrhage

LVO Left ventricular output

LA/Ao Ratio of left atrial to aortic root diameter

LVEDd Left ventricular end-diastolic diameter

LPA Left pulmonary artery

NEC Necrotizing enterocolitis

PDA Patent ductus arteriosus

PFO Patent foramen ovale

PNAC Parenteral nutrition-associated cholestasis

POLUS Point-of-care ultrasound

RDS Respiratory distress syndrome

ROP Retinopathy of prematurity

VSD Ventricular septal defects

\section{Introduction}

Patent ductus arteriosus (PDA) is a major cause of cardiovascular compromise during transition from fetal to neonatal circulation in premature infants [1]. PDA is usually 
accompanied by significant left-to-right shunt through the ductus arteriosus (DA) and can be confirmed by echocardiography. Clinical manifestations include systemic hypoperfusion and pulmonary hyperperfusion [2]. Furthermore, severe morbidities, such as acute kidney injury (AKI), pulmonary hemorrhage, intraventricular hemorrhage (IVH), necrotizing enterocolitis (NEC), bronchopulmonary dysplasia (BPD), and increased mortality, are associated with PDA [3-7]. Conventionally, treatment options for PDA include the administration of non-steroidal anti-inflammatory drugs (NSAIDs) and/or surgical ligation if conservative treatment fails in premature infants. However, there are few consensus on the management of PDA, including whether, when, and how to treat, and few clinical studies on early serial daily echocardiographic assessment of the hemodynamics of PDA to predict whether pharmacologic or surgical treatment are required in the very preterm infants. Therefore, we performed this study to assess the characteristics of DA, indices of pulmonary overcirculation, and systemic shunt effect continuously and dynamically and constructed a model with echocardiographic indices to predict the probability of PDA that ultimately requires intervention.

\section{Methods}

With the approval of the Ethics Committee of the Children's Hospital, Zhejiang University School of Medicine (IRB No. 2018-IRB-073), a prospective observational study was conducted to investigate the clinical data and echocardiographic indices of 42 preterm infants born at gestational age (GA) $\leq 30$ weeks who were admitted to the neonatal intensive care unit of the Children's Hospital, Zhejiang University School of Medicine from October 2018 to December 2020. Written informed consent was obtained from guardian participants. The exclusion criteria for this study were as follows: (1) the age at admission was $>12 \mathrm{~h}$ after birth; (2) infants who died or gave up treatment within $72 \mathrm{~h}$ of life; (3) infants complicated with complex congenital heart disease except for a small patent foramen ovale (PFO)/atrial septal defect (ASD)/ventricular septal defect (VSD); (4) the parents refused. In this study, we divided the patients into intervention group and non-intervention group according to whether PDA was treated or not during hospitalization: (1) intervention group: closure with oral non-steroidal antiinflammatory drugs (NSAIDs) and/or surgical ligation; (2) non-intervention group: spontaneous closure without pharmacologic or surgical treatment.

The indications for treatment were based on whether PDA was symptomatic including respiratory compromise (e.g., requiring persistent mechanical support), cardiac insufficiency, or large left-to-right ductus shunt with evidence of hemodynamic compromise, such as reversal of flow in the descending aorta during diastole, feeding intolerance, oliguria, hypotension, or wide pulse pressure in the study. Pharmacologic treatment was considered if conservative measures have failed to control the above symptoms from the second week after birth. PDA surgical ligation was generally performed in the patients which NSAIDs treatment was unsuccessful after the end of the two course or contraindicated.

Transthoracic echocardiography was performed using GE Vivid ${ }^{\mathrm{TM}}$ iq bedside ultra-portable Doppler diagnostic ultrasound system with a 12S-RS transducer (GE Healthcare). We routinely assessed cardiac function (EF, FS, E:A, and E:E'), PDA characteristics (patency, dimension), indices of left heart volume ((LA:Ao, left ventricular enddiastolic diameter (LVEDd), end-diastolic velocity of the left pulmonary artery (LPA), left ventricular output (LVO)) and pressure (mitral valve E:A) loading, and the presence of retrograde diastolic blood flow in a post-ductal artery (descending aorta, DAo) in participants at postnatal age of 0-12 h, $24 \mathrm{~h}, 48 \mathrm{~h}$, and $72 \mathrm{~h}$, respectively. The serial daily echocardiographic assessments were performed by the same neonatologist who had received the training of critical ultrasound course. The data of patients' demographics and clinical outcomes were recorded.

\section{Statistical Analysis}

Statistical analysis was performed using the SPSS version 21.0 and GraphPad Prism 7.00. We compared the echocardiographic data of the intervention group and the nonintervention group. Statistical analysis was performed using $t$ test and Mann-Whitney $u$ tests for continuous variables according to whether variables obey normal distribution or not. $\mathrm{X}^{2}$ or Fisher exact tests were used for categorical variables as appropriate. Data were expressed as median with quartile range $(\mathrm{M}(\mathrm{Q} 1, \mathrm{Q} 3))$ for continuous variables or as a percentage of patients in a given categorical variable. All probability $(p)$ values were two-tailed and a value less than 0.05 was considered statistically significant.

Univariate and multivariate regression analyses were used to analyze the data variables of echocardiography to determine predictors of PDA requiring NSAIDs intervention and/ or surgical ligation. Multivariable logistic regression analysis was performed to analyze the variables at postnatal age of 0-12 h, $24 \mathrm{~h}, 48 \mathrm{~h}$, and $72 \mathrm{~h}$, respectively, which using stepwise logistic regression with forward selection and backward elimination by removing variables that had a $p$ value of greater than 0.05 . Results were expressed as OR with $95 \%$ CI. The predictive power of multivariable model was evaluated by the receiver operating characteristic (ROC) curve and the area under the curve (AUC). Based on the results of the multivariable regression analysis, which the 
largest AUC was chosen. Cut-off values of the results were chosen on the basis of the ROC curve of each variable and outcome, which located in the maximum value of Youden Index according to the sensitivity and specificity.

\section{Results}

A total of forty-two very preterm infants met the inclusion criteria and were enrolled during the study period (Fig. 1). These were categorized into two groups: 15 $(35.7 \%)$ in the intervention group: gestational age (GA) was $27.2 \pm 1.1$ weeks and birth weight ranged from 750 to $960 \mathrm{~g}$ (median $880 \mathrm{~g}$ ) and 27 (64.3\%) in the non-intervention group: GA was $28.8 \pm 1.5$ weeks and birth weight ranged from 950 to $1340 \mathrm{~g}$ (median $1050 \mathrm{~g}$ ). Compared with the non-intervention group, the intervention group had a higher proportion of alveolar surfactant use $(p=0.008)$, reintubation within $48 \mathrm{~h}$ from extubation $(p=0.047)$, duration of mechanical ventilation $(p<0.001)$, inhale oxygen days $(p=0.005)$, inotropes/vasopressors use $(p<0.001)$, extrauterine growth retardation (EUGR) $(p=0.029)$, IVH grade $\geq 3$ ( $p=0.016)$, and retinopathy of prematurity (ROP) $(p=0.004)$. The mortality and other clinical manifestations were not statistically significant between the two groups (Table 1).

The diameter of the DA in preterm infants of the intervention group increased gradually within $72 \mathrm{~h}$ after birth, while the trend in the non-intervention group was completely opposite. Compared with the non-intervention group, the diameters of DA at postnatal age of 0-12 h, $24 \mathrm{~h}, 48 \mathrm{~h}$, and $72 \mathrm{~h}$ in the intervention group were larger, with significant statistical difference $(p=0.028, p<0.001, p<0.001$, and $p<0.001$, respectively). In addition, two groups had statistically significant difference compared with echocardiographic indices of pulmonary overcirculation, including LVO at postnatal age of $24 \mathrm{~h}, 48 \mathrm{~h}$, and $72 \mathrm{~h}(p=0.001, p=0.007$, and $p=0.002$, respectively), LA/Ao at postnatal age of $72 \mathrm{~h}$ $(p<0.001)$, and end-diastolic flow of the LPA at $24 \mathrm{~h}, 48 \mathrm{~h}$, and $72 \mathrm{~h}(p=0.026, p<0.001$, and $p<0.001$, respectively). The presence of retrograde diastolic blood flow of the DAo represents an index of systemic shunt effect. The incidence of diastolic reverse flow of the DAo was $26.7 \%, 80 \%$, and $86.7 \%$ at postnatal age of $24 \mathrm{~h}, 48 \mathrm{~h}$, and $72 \mathrm{~h}$, respectively, in the intervention group, which were significantly higher than those of the non-intervention group $(0.0 \%, 14.8 \%$, and $18.5 \%, p=0.012, p<0.001$, and $p<0.001$, respectively). The other parameters of left ventricular systolic and diastolic function except for mitral valve $\mathrm{E} / \mathrm{E}^{\prime}$ at the postnatal age of $72 \mathrm{~h}(p=0.014)$ were not statistically significant between the two groups (Table 2).

\section{Risk Factors for PDA that Need Pharmacologic and/or Surgical Ligation Intervention Analyzed by Logistic Regression Analysis}

There were fourteen statistically significant variables (one variable at postnatal age of $0-12 \mathrm{~h}$, three variables at
Fig. 1 Flowchart of enrolled participants

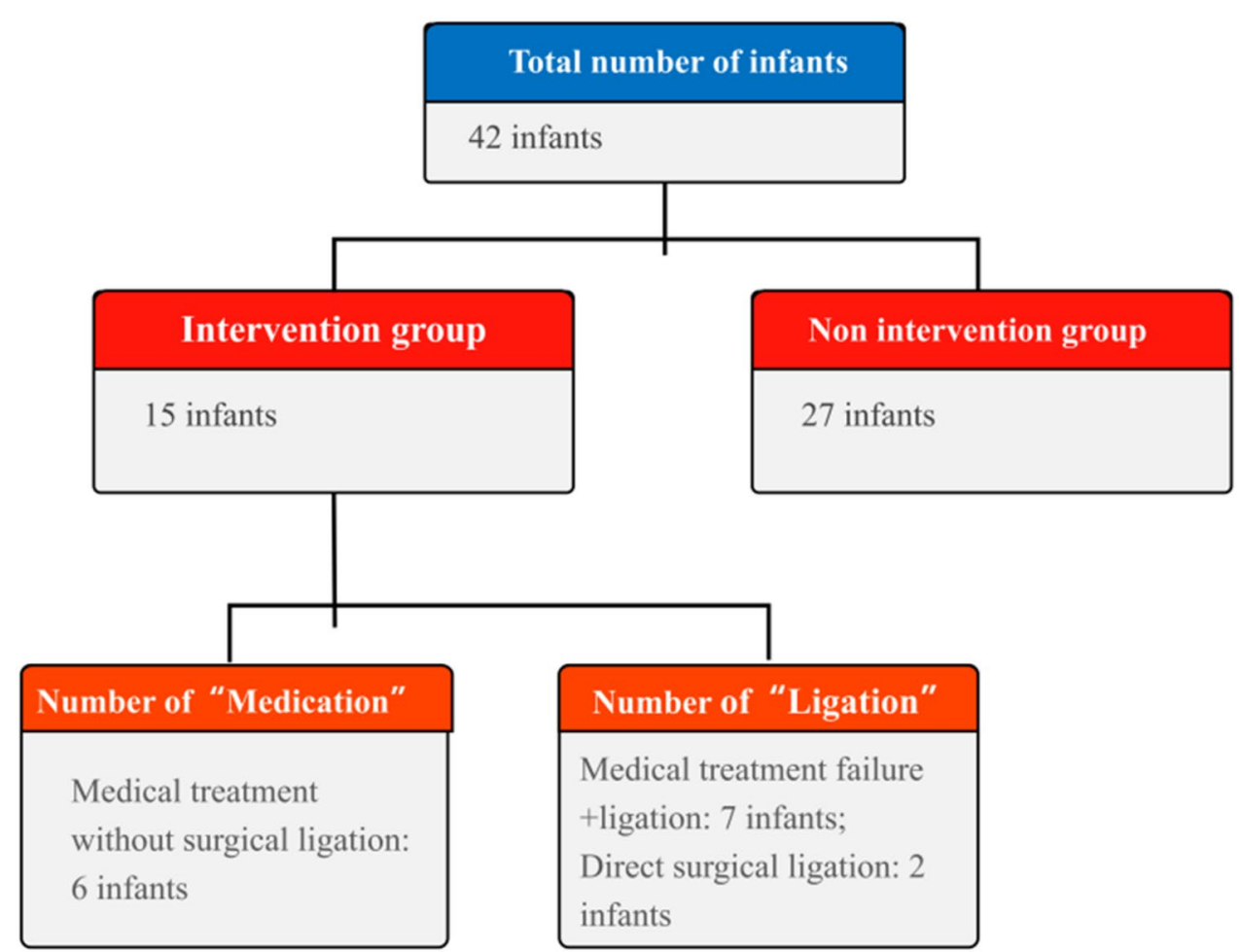


Table 1 Comparison of the demographic and clinical characteristics of the study cohort

\begin{tabular}{|c|c|c|c|}
\hline & $\begin{array}{l}\text { Intervention group } \\
(n=15)\end{array}$ & $\begin{array}{l}\text { Non-intervention } \\
\text { group }(n=27)\end{array}$ & $p$ Value \\
\hline \multicolumn{4}{|l|}{ Clinical Characters } \\
\hline Male gender & $10(66.7 \%)$ & $17(63 \%)$ & 0.81 \\
\hline Gestational age, weeks* & $27.2 \pm 1.1$ & $28.8 \pm 1.5$ & 0.001 \\
\hline Birth weight, $g^{*}$ & $880(750-960)$ & $1050(950-1340)$ & 0.001 \\
\hline Use of surfactant* & $13(86.7 \%)$ & $12(44.4 \%)$ & 0.008 \\
\hline Reintubation within $48 \mathrm{~h}$ from extubation * & $4(26.7 \%)$ & $1(3.7 \%)$ & 0.047 \\
\hline Duration of mechanical ventilation* & $25.7 \pm 20.5$ & $3.6 \pm 6.1$ & $<0.001$ \\
\hline Non-invasive ventilation & $30.7 \pm 18.9$ & $20 \pm 17.1$ & 0.068 \\
\hline Inhale oxygen days* & $70.5 \pm 36.6$ & $38.1 \pm 32.4$ & 0.005 \\
\hline BPD & $14(93.3 \%)$ & $17(63 \%)$ & 0.075 \\
\hline VAP/Lower respiratory infection & $8(53.3 \%)$ & $9(33.3 \%)$ & 0.206 \\
\hline Late onset sepsis & $8(53.3 \%)$ & $9(3.3 \%)$ & 0.206 \\
\hline Use of inotropes/vasopressors* & $10(66.7 \%)$ & $2(7.4 \%)$ & $<0.001$ \\
\hline Feeding intolerance & $14(93.3 \%)$ & $17(63 \%)$ & 0.075 \\
\hline Total enteral feeding & $45(39-70)$ & $38(20-65)$ & 0.27 \\
\hline PNAC & $5(33.3 \%)$ & $7(25.9 \%)$ & 0.879 \\
\hline EUGR* & $9(60 \%)$ & $7(25.9 \%)$ & 0.029 \\
\hline $\mathrm{ROP}^{*}$ & $10(66.7 \%)$ & $6(22.2 \%)$ & 0.004 \\
\hline Length of hospital stay & $88(62-100)$ & $60(44-77)$ & 0.059 \\
\hline \multicolumn{4}{|l|}{ Complications and mortality } \\
\hline NEC any stage & $2(13.3 \%)$ & $5(18.5 \%)$ & 1.000 \\
\hline Pulmonary hemorrhage & $5(33.3 \%)$ & $2(7.4 \%)$ & 0.077 \\
\hline IVH grade $\geq 3 *$ & $5(33.3 \%)$ & $1(3.7 \%)$ & 0.016 \\
\hline Death & $3(20 \%)$ & $2(7.4 \%)$ & 0.329 \\
\hline
\end{tabular}

$B P D$ Bronchopulmonary dysplasia, VAP Ventilator-associated pneumonia, PNAC Parenteral nutrition-associated cholestasis, EUGR Extrauterine growth retardation, ROP Retinopathy of prematurity, NEC Necrotizing enterocolitis, $I V H$ Intraventricular hemorrhage

*Indicates parameters found to be statistically significant $(p<0.05)$ postnatal age of $24 \mathrm{~h}$, four variables at postnatal age of $48 \mathrm{~h}$, and six variables at postnatal age of $72 \mathrm{~h}$ ) according to univariable logistic regression analysis where PDA requiring NSAIDs intervention and/or surgical ligation was used as the dependent variable, while each continuous variable and categorical variable was used as the independent variable (Tables 3, 4, 5, 6). For the variables that showed no statistically significant difference, but were proven in previous trials, they were still included in the multivariate regression analysis. We, respectively, conducted four times multivariate regression analysis according to the time period of ultrasound screening and the variables included EF, E/E', PDA size/weight, LVO, LA/Ao, LVEDd, end-diastolic flow of the LPA, and retrograde diastolic blood flow of DAo in each regression analysis model. There was only one statistically significant variable in the first three models (PDA size/ weight at 0-12 h, LVO at $24 \mathrm{~h}$, PDA size/weight at $48 \mathrm{~h}$ ) and two statistically significant variables (PDA size/weight at $72 \mathrm{~h}$ and LA/Ao at $72 \mathrm{~h}$ ) in the fourth model, with backward selection were retained in each model (Table 7). The $\mathrm{ROC}$ of the four models was drawn with the variables and outcome, and the area under curve (AUC) was $0.731(95 \% \mathrm{CI}$ $0.57-0.89, p=0.014), 0.877$ (95\%CI 0.75-1, $p<0.001)$, 0.915 (95\%CI 0.83-1, $p<0.001$ ), and 0.958 (95\%CI 0.9-1, $p<0.001$ ), respectively (Fig. 2). The largest AUC was seen in the combined indicators of PDA size/weight and LA/Ao at postnatal age of $72 \mathrm{~h}$ in the fourth model. Cut-off values of the variables were $3.2 \mathrm{~mm} / \mathrm{kg}$ and 1.4 for PDA size/weight and LA/Ao, respectively, with sensitivity and specificity of $100 \%$ and $88.9 \%$, respectively.

\section{Discussion}

Previous studies have demonstrated that PDA is associated with many early and late adverse outcomes [3-7]. In the present study, we identified an inverse relationship between the need for drug treatment and/or ligation in PDA and gestational age and birth weight. The DA leftto-right shunt can result in an interstitial and alveolar pulmonary edema and decreased lung compliance, which leads to higher ventilator settings prolonged ventilation 
Table 2 Comparison of the ultrasound parameter of the study cohort

\begin{tabular}{|c|c|c|c|}
\hline & Intervention $\operatorname{group}(n=15)$ & Non-intervention group $(n=27)$ & $p$ Value \\
\hline \multicolumn{4}{|c|}{ Variables at postnatal age of $0-12 \mathrm{~h}$} \\
\hline $\mathrm{EF}$ & $67.8 \pm 6.5$ & $65 \pm 8.2$ & 0.263 \\
\hline FS & $35(31-37)$ & $33(27-36)$ & 0.193 \\
\hline $\mathrm{E} / \mathrm{A}$ & $0.88 \pm 0.19$ & $0.8 \pm 0.11$ & 0.157 \\
\hline $\mathrm{E} / \mathrm{E}^{\prime}$ & $11.5(9.3-17)$ & $9.7(7.8-13.7)$ & 0.253 \\
\hline PDA size/weight(mm/kg)* & $2.6 \pm 0.7$ & $2.1 \pm 0.7$ & 0.028 \\
\hline $\mathrm{LVO}(\mathrm{ml} / \mathrm{kg} \cdot \mathrm{min})$ & 190.4(149.1-199.7) & $168.1(144.5-186.4)$ & 0.265 \\
\hline $\operatorname{LVEDd}(\mathrm{mm})$ & $1.1(1-1.3)$ & $1.2(1.1-1.4)$ & 0.105 \\
\hline LA/Ao & $1.3(1.2-1.4)$ & $1.4(1.3-1.5)$ & 0.109 \\
\hline $\operatorname{LPA}(\mathrm{m} / \mathrm{s})$ & $0.17(0.1-0.22)$ & $0.13(0.1-0.21)$ & 0.937 \\
\hline DAo & 0 & 0 & - \\
\hline \multicolumn{4}{|l|}{ Variables at postnatal age of $24 \mathrm{~h}$} \\
\hline $\mathrm{EF}$ & $67.1 \pm 10.2$ & $64.9 \pm 9.3$ & 0.466 \\
\hline FS & $32(28-39)$ & $32(27-38)$ & 0.608 \\
\hline $\mathrm{E} / \mathrm{A}$ & $0.88(0.8-1.1)$ & $0.84(0.78-0.9)$ & 0.168 \\
\hline $\mathrm{E} / \mathrm{E}^{\prime}$ & $14.8(8.8-16.3)$ & $10.3(9.3-12.3)$ & 0.074 \\
\hline PDA size/weight $(\mathrm{mm} / \mathrm{kg})^{*}$ & $3.1 \pm 0.8$ & $1.8 \pm 0.9$ & $<0.001$ \\
\hline $\mathrm{LVO}(\mathrm{ml} / \mathrm{kg} \cdot \mathrm{min})^{*}$ & $282.8 \pm 71.4$ & $202.9 \pm 30.4$ & 0.001 \\
\hline $\operatorname{LVEDd}(\mathrm{mm})$ & $1.21 \pm 0.13$ & $1.26 \pm 0.2$ & 0.401 \\
\hline LA/Ao & 1.4(1.3-1.6) & $1.4(1.3-1.6)$ & 0.631 \\
\hline $\operatorname{LPA}(\mathrm{m} / \mathrm{s})^{*}$ & $0.21(0.15-0.23)$ & $0.12(0.1-0.18)$ & 0.026 \\
\hline $\mathrm{DAo}^{*}$ & $4(26.7 \%)$ & $0(0.0 \%)$ & 0.012 \\
\hline \multicolumn{4}{|c|}{ Variables at postnatal age of $48 \mathrm{~h}$} \\
\hline $\mathrm{EF}$ & $69.4 \pm 4.6$ & $67.7 \pm 7.7$ & 0.368 \\
\hline FS & $9.7(7.8-13.7)$ & $34.6 \pm 5.3$ & 0.591 \\
\hline $\mathrm{E} / \mathrm{A}$ & $0.87(0.78-1.1)$ & $0.87(0.8-0.95)$ & 0.979 \\
\hline $\mathrm{E} / \mathrm{E}^{\prime}$ & $13.3(7.6-19.3)$ & $9.5(8-12.7)$ & 0.185 \\
\hline PDA size/weight $(\mathrm{mm} / \mathrm{kg})^{*}$ & $3.4 \pm 0.9$ & $1.6 \pm 1.1$ & $<0.001$ \\
\hline $\mathrm{LVO}(\mathrm{ml} / \mathrm{kg} \cdot \mathrm{min})^{*}$ & $313.2 \pm 90.9$ & $234.9 \pm 58.2$ & 0.007 \\
\hline $\operatorname{LVEDd}(\mathrm{mm})$ & $1.27 \pm 0.17$ & $1.31 \pm 0.22$ & 0.563 \\
\hline LA/Ao & $1.5 \pm 0.1$ & $1.5 \pm 0.2$ & 0.055 \\
\hline $\operatorname{LPA}(\mathrm{m} / \mathrm{s})^{*}$ & $0.24(0.2-0.26)$ & $0.12(0.09-0.2)$ & $<0.001$ \\
\hline DAo* & $12(80 \%)$ & $4(14.8 \%)$ & $<0.001$ \\
\hline \multicolumn{4}{|c|}{ Variables at postnatal age of $72 \mathrm{~h}$} \\
\hline $\mathrm{EF}$ & $70.5 \pm 7.3$ & $67.1 \pm 7.9$ & 0.183 \\
\hline FS & $36.7 \pm 6.1$ & $34.3 \pm 5.9$ & 0.230 \\
\hline $\mathrm{E} / \mathrm{A}$ & $0.92 \pm 0.2$ & $0.85 \pm 0.11$ & 0.227 \\
\hline $\mathrm{E} / \mathrm{E}^{\prime} *$ & $16.2 \pm 7.3$ & $11.7 \pm 4.0$ & 0.014 \\
\hline PDA size/weight(mm/kg)* & $3.6(3.2-3.8)$ & $1.5(0-2.1)$ & $<0.001$ \\
\hline $\mathrm{LVO}(\mathrm{ml} / \mathrm{kg} \cdot \min ) *$ & $343.8 \pm 89.1$ & $251.3 \pm 57.8$ & 0.002 \\
\hline $\operatorname{LVEDd}(\mathrm{mm})$ & $1.31 \pm 0.18$ & $1.3 \pm 0.2$ & 0.879 \\
\hline LA/Ao* & $1.6(1.5-1.7)$ & $1.3(1.2-1.5)$ & $<0.001$ \\
\hline $\operatorname{LPA}(\mathrm{m} / \mathrm{s})^{*}$ & $0.24(0.22-0.26)$ & $0.12(0.1-0.2)$ & $<0.001$ \\
\hline $\mathrm{DAo}^{*}$ & $13(86.7 \%)$ & $5(18.5 \%)$ & $<0.001$ \\
\hline
\end{tabular}

*Indicates parameters found to be statistically significant $(p<0.05)$ with the period of oxygen inhalation, and increased risk of pulmonary hemorrhage and BPD [8,9]. RDS will also aggravate this process as a result of low plasma oncotic pressure and increased capillary permeability, as confirmed by a previous study [10]. Our study shows that the preterm infants in the PDA intervention group required more pulmonary surfactant, longer mechanical ventilation, and oxygen demand. However, there was no significant 
Table 3 Results of univariate regression analysis of variables at postnatal age of $0-12 \mathrm{~h}$

\begin{tabular}{lrllllllrr}
\hline Variables & \multicolumn{1}{l}{$\beta$} & SE & Wald & df & $p$ Value & OR & \multicolumn{2}{l}{ 95\%CI } \\
\cline { 7 - 10 } & & & & & & & & Lower & Upper \\
\hline EF & 0.050 & 0.044 & 1.276 & 1 & 0.259 & 1.051 & 0.964 & 1.146 \\
FS & 0.049 & 0.059 & 0.690 & 1 & 0.406 & 1.050 & 0.936 & 1.178 \\
E/A & 3.923 & 2.452 & 2.559 & 1 & 0.11 & 50.527 & 0.413 & 6174.457 \\
E/E' & 0.073 & 0.062 & 1.372 & 1 & 0.242 & 1.075 & 0.952 & 1.214 \\
PDA size /weight (mm/kg)* & 1.023 & 0.496 & 4.248 & 1 & 0.039 & 2.782 & 1.052 & 7.360 \\
LVO(ml/kg.min) & 0.010 & 0.008 & 1.382 & 1 & 0.240 & 1.010 & 0.994 & 1.026 \\
LVEDd(mm) & -3.216 & 2.096 & 2.355 & 1 & 0.125 & 0.04 & 0.001 & 2.439 \\
LA/Ao & -3.496 & 2.202 & 2.520 & 1 & 0.112 & 0.03 & 0.000 & 2.271 \\
LPA(m/s) & 0.736 & 5.420 & 0.018 & 1 & 0.892 & 2.088 & 0.000 & $85,762.875$ \\
\hline
\end{tabular}

*Indicates parameters found to be statistically significant $(p<0.05)$

Table 4 Results of univariate regression analysis of variables at postnatal age of $24 \mathrm{~h}$

\begin{tabular}{|c|c|c|c|c|c|c|c|c|}
\hline \multirow[t]{2}{*}{ Variables } & \multirow[t]{2}{*}{$\beta$} & \multirow[t]{2}{*}{ SE } & \multirow[t]{2}{*}{ Wald } & \multirow[t]{2}{*}{$\mathrm{df}$} & \multirow[t]{2}{*}{$p$ Value } & \multirow[t]{2}{*}{ OR } & \multicolumn{2}{|l|}{$95 \% \mathrm{CI}$} \\
\hline & & & & & & & Lower & Upper \\
\hline $\mathrm{EF}$ & 0.025 & 0.034 & 0.555 & 1 & 0.456 & 1.026 & 0.959 & 1.097 \\
\hline FS & 0.032 & 0.044 & 0.534 & 1 & 0.465 & 1.033 & 0.948 & 1.125 \\
\hline $\mathrm{E} / \mathrm{A}$ & 4.707 & 2.558 & 3.388 & 1 & 0.066 & 110.755 & 0.737 & $16,646.885$ \\
\hline $\mathrm{E} / \mathrm{E}^{\prime}$ & 0.107 & 0.076 & 2.009 & 1 & 0.156 & 1.113 & 0.96 & 1.291 \\
\hline PDA size /weight $(\mathrm{mm} / \mathrm{kg})^{*}$ & 1.841 & 0.610 & 9.099 & 1 & 0.003 & 6.305 & 1.906 & 20.859 \\
\hline $\mathrm{LVO}(\mathrm{ml} / \mathrm{kg} \cdot \mathrm{min})^{*}$ & 0.049 & 0.016 & 8.906 & 1 & 0.003 & 1.050 & 1.017 & 1.084 \\
\hline LVEDd(mm) & -1.554 & 1.819 & 0.730 & 1 & 0.393 & 0.211 & 0.006 & 7.475 \\
\hline LA/Ao & 1.104 & 1.969 & 0.314 & 1 & 0.575 & 3.017 & 0.064 & 143.194 \\
\hline $\mathrm{LPA}(\mathrm{m} / \mathrm{s})$ & 9.920 & 5.407 & 3.367 & 1 & 0.067 & $20,333.299$ & 0.508 & $813,311,747.2$ \\
\hline DAo* & 22.101 & $20,096.485$ & 0.000 & 1 & 0.999 & $3,965,256,485$ & 0.000 & - \\
\hline
\end{tabular}

*Indicates parameters found to be statistically significant $(p<0.05)$

Table 5 Results of univariate regression analysis of variables at postnatal age of $48 \mathrm{~h}$

\begin{tabular}{lrlllllll}
\hline Variables & \multicolumn{1}{l}{$\beta$} & & SE & Wald & df & $p$ Value & OR & \multicolumn{2}{l}{$95 \% \mathrm{CI}$} \\
\cline { 5 - 9 } & & & & & & & Lower & Upper \\
\hline EF & 0.040 & 0.050 & 0.638 & 1 & 0.424 & 1.041 & 0.943 & 1.149 \\
FS & 0.038 & 0.069 & 0.304 & 1 & 0.582 & 1.039 & 0.907 & 1.190 \\
E/A & 2.035 & 2.444 & 0.693 & 1 & 0.405 & 7.653 & 0.064 & 920.505 \\
E/E' & 0.057 & 0.055 & 1.062 & 1 & 0.303 & 1.059 & 0.95 & 1.18 \\
PDA size/weight (mm/kg)* & 1.777 & 0.569 & 9.752 & 1 & 0.002 & 5.912 & 1938 & 18.036 \\
LVO(ml/kg.min)* & 0.015 & 0.006 & 7.209 & 1 & 0.007 & 1.015 & 1.004 & 1.026 \\
LVEDd(mm) & -0.992 & 1.673 & 0.352 & 1 & 0.553 & 0.371 & 0.014 & 9.832 \\
LA/Ao & 4.370 & 2.338 & 3.494 & 1 & 0.062 & 79.069 & 0.809 & 7730.881 \\
LPA(m/s)* & 26.087 & 7.968 & 10.718 & 1 & 0.001 & $2.135 \mathrm{E}+11$ & $35,219.833$ & $1.294 \mathrm{E}+18$ \\
DAo* & -3.135 & 0.843 & 13.844 & 1 & 0.000 & 23.000 & 4.410 & 119.960 \\
\hline
\end{tabular}

*Indicates parameters found to be statistically significant $(p<0.05)$ difference in the incidence of pulmonary hemorrhage and BPD between the intervention group and non-intervention groups. This may be attributed to the small sample size used in our study. Furthermore, the presence of a PDA can result in systemic hypoperfusion that is associated with several morbidities, including hypotension and IVH, as confirmed by our study $[4,5,10,11]$.

Worthy of note is the fact that a significant shunt through the DA may remain clinically "silent" during the first few days of life $[2,12]$. This is demonstrated in our study where 
Table 6 Results of univariate regression analysis of variables at postnatal age of $72 \mathrm{~h}$

\begin{tabular}{lclrllllll}
\hline Variables & $\beta$ & SE & Wald & df & $p$ Value & OR & \multicolumn{2}{l}{ 95\%CI } \\
\cline { 5 - 9 } & & & & & & & Lower & Upper \\
\hline EF & 0.059 & 0.045 & 1.773 & 1 & 0.183 & 1.061 & 0.972 & 1.158 \\
FS & 0.068 & 0.056 & 1.459 & 1 & 0.227 & 1.071 & 0.958 & 1.196 \\
E/A & 3.120 & 2.221 & 1.972 & 1 & 0.16 & 22.639 & 0.291 & 1760.625 \\
E/E'* & 0.160 & 0.072 & 4.893 & 1 & 0.027 & 1.174 & 1.018 & 1.352 \\
PDA size/weight (mm/kg)* & 1.896 & 0.592 & 10.270 & 1 & 0.001 & 6.661 & 2.089 & 21.242 \\
LVO(ml/kg.min)* & 0.017 & 0.006 & 8.778 & 1 & 0.003 & 1.017 & 1.006 & 1.029 \\
LVEDd(mm) & 0.265 & 1.691 & 0.025 & 1 & 0.875 & 1.303 & 0.047 & 35.817 \\
LA/Ao* & 7.077 & 2.257 & 9.832 & 1 & 0.002 & 1183.942 & 14.199 & $98,717.018$ \\
LPA(m/s)* & 18.038 & 6.270 & 8.276 & 1 & 0.004 & $68,217,631.55$ & 313.726 & $1.483 \mathrm{E}+13$ \\
DAo* & 3.353 & 0.907 & 13.674 & 1 & 0.000 & 28.600 & 4.836 & 169.153 \\
\hline
\end{tabular}

*Indicates parameters found to be statistically significant $(p<0.05)$

Table 7 Multivariable predictors of PDA that need to be treated with NSAIDs and/or surgical ligation in the predictive models

\begin{tabular}{|c|c|c|c|c|c|c|c|c|c|}
\hline \multirow[t]{2}{*}{ Model } & \multirow[t]{2}{*}{ Variables } & \multirow[t]{2}{*}{$\beta$} & \multirow[t]{2}{*}{ SE } & \multirow[t]{2}{*}{ Wald } & \multirow[t]{2}{*}{ df } & \multirow[t]{2}{*}{$p$ Value } & \multirow[t]{2}{*}{ OR } & \multicolumn{2}{|l|}{$95 \% \mathrm{CI}$} \\
\hline & & & & & & & & Lower & Upper \\
\hline \multirow[t]{2}{*}{ Model 1} & PDA size/weight at $0-12 \mathrm{~h}(\mathrm{~mm} / \mathrm{kg})$ & 1.023 & .496 & 4.248 & 1 & 0.039 & 2.782 & 1.052 & 7.360 \\
\hline & Intercept & -3.012 & 1.243 & 5.873 & 1 & 0.015 & 0.049 & & \\
\hline \multirow[t]{2}{*}{ Model 2} & $\mathrm{LVO}$ at $24 \mathrm{~h}(\mathrm{ml} / \mathrm{kg} \cdot \mathrm{min})$ & .049 & .016 & 8.906 & 1 & 0.003 & 1.050 & 1.017 & 1.084 \\
\hline & Intercept & -11.862 & 3.800 & 9.745 & 1 & 0.002 & 0.000 & & \\
\hline \multirow[t]{2}{*}{ Model 3} & PDA size/weight at $48 \mathrm{~h}(\mathrm{~mm} / \mathrm{kg})$ & 1.777 & 0.569 & 9.752 & 1 & 0.002 & 5.912 & 1.938 & 18.036 \\
\hline & Intercept & -5.036 & 1.566 & 10.338 & 1 & 0.001 & 0.007 & & \\
\hline \multirow[t]{3}{*}{ Model 4} & PDA size/weight at $72 \mathrm{~h}(\mathrm{~mm} / \mathrm{kg})$ & 1.876 & 649 & 8.357 & 1 & 0.004 & 6.530 & 1.830 & 23.305 \\
\hline & LA/Ao at $72 \mathrm{~h}$ & 8.199 & 4.032 & 4.134 & 1 & 0.042 & 3635.779 & 1.343 & $9,839,607.803$ \\
\hline & Intercept & -18.280 & 7.344 & 6.196 & 1 & 0.008 & 0.000 & & \\
\hline
\end{tabular}

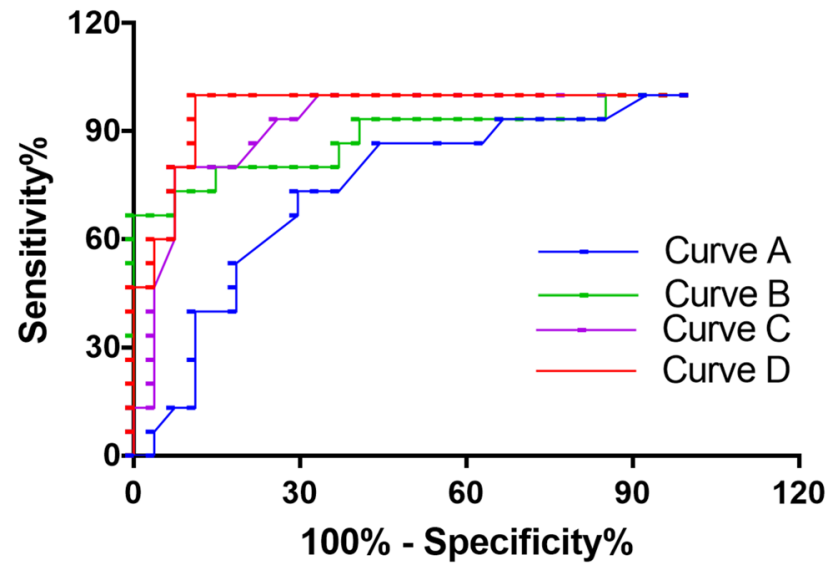

Fig. 2 Receiver operating characteristic curves (ROC) for predicting PDA that need to be treated with NSAIDs and/or surgical ligation. Curve A: PDA size/weight at postnatal age of 0-12 h; curve B: LVO at postnatal age of $24 \mathrm{~h}$; curve C: PDA size/weight at postnatal age of $48 \mathrm{~h}$; curve D: PDA size/weight and LA/Ao at postnatal age of $72 \mathrm{~h}$ a lack of clinical evidence of hsPDA in the intervention group was accompanied by significant pulmonary overcirculation and systemic shunt effect within $72 \mathrm{~h}$ after birth, as identified using ultrasound indicators. Therefore, we used a combination of echocardiographic indices to construct a predictive model of PDA with a sensitivity and specificity of $100 \%$ and $88.9 \%$, respectively. Consequently, our predictive model was helpful in predicting high risk of PDA requiring NSAIDs intervention and/or surgical ligation.

Transductal diameter has been identified as the most commonly used hsPDA indicator. Several clinical studies have identified transductal diameter as a risk factor for developing PDA [2, 13-15]. Transductal shunt volume is largely determined by the dimension of the shunt [16]. Clinical investigators have classified absolute PDA diameter into small $(<1.5)$, moderate $(1.5-2.0)$, and large $(\geq 2.0)$, respectively [17]. In the present study, we measured the diameter of ductus at its narrowest point corresponding to the pulmonary artery end, by direct view or color Doppler, and chose the ratio of diameter to patient's weight as the variable, instead of an absolute value. This option was considered because of the significant difference in birth weight between the two 
groups in this study. In a previous study, L Storme found that the PDA size/weight $>1.4 \mathrm{~mm} / \mathrm{kg}$ measured within $48 \mathrm{~h}$ after birth is a good indicator of hsPDA [18]. In addition, Kwinta reported that a PDA size/weight $>1.5 \mathrm{~mm} / \mathrm{kg}$ measured $12-48 \mathrm{~h}$ after birth is a predictive index for PDA requiring surgical ligation [19]. Furthermore, Harling used PDA size/weight $\geq 2 \mathrm{~mm} / \mathrm{kg}$ measured at $72 \mathrm{~h}$ of age as the predictive index for PDA requiring treatment [15]. However, our study found that PDA size/weight $>3.2 \mathrm{~mm} / \mathrm{kg}$ at postnatal age of $72 \mathrm{~h}$ could be used as a predictive factor for infants with PDA requiring oral NSAIDs treatment and/or surgical ligation.

A large amount of transductal left-to-right shunt increases pulmonary blood flow and pulmonary venous return. Consequently, this increases the left-side heart volume loading, leading to dilatation of the left atrium and ventricle from increased preload, especially in the absence of a large intraatrial shunt during the cardiovascular transition stage [20]. Hence, a ratio of LA/Ao can be used as a surrogate index of pulmonary overcirculation and hsPDA [21, 22]. Many previous clinical trials reported that LA/Ao ratio of $>1.5$ is a predictor of hsPDA [2, 23, 24]. In our study, LA/Ao was obtained from the parasternal long-axis view using a plain 2D image and the final result is consistent with previous trials, demonstrating that LA/Ao $>1.4$ at postnatal age of $72 \mathrm{~h}$ can be used as a risk factor for predicting PDA requiring treatment. Studies have demonstrated that LVO, which represents pulmonary blood flow, could be a predictive factor for hsPDA requiring intervention. High LVO value is often associated with a large left-to-right shunt through the PDA and pulmonary overcirculation [25]. A previous study reported that a cut-off of $\mathrm{LVO}>300 \mathrm{ml} / \mathrm{kg} / \mathrm{min}$ was associated with the clinical presence of hsPDA [2]. Another previous study demonstrated that the ratio of the LVO to superior vena cava flow is directly proportional to the ductus flow and, when $\geq 4$, may indicate hemodynamic significance [26]. Our results show that $\mathrm{LVO}>251.7 \mathrm{ml} / \mathrm{kg}$.min at postnatal age of $24 \mathrm{~h}$ (sensitivity was $66.7 \%$, specificity was $100 \%$ ) could be used as a predictive factor for hsPDA requiring treatment.

The limitations of the present study are as follows: firstly, the indices of pulmonary overcirculation, such as LVEDd, end-diastolic velocity of LPA and mitral valve E/A, and systemic shunt effect such as retrograde blood flow of descending aorta during the first few days after birth, could not be used as risk factors to predict the necessity of therapy for PDA in our study. This is inconsistent with the results of some previous reports [27-29]. This inconsistency may be related to our sample size and needs further investigation. Secondly, in our study, we only used echocardiography indices as a predictor for PDA and did not include these clinical characteristics such as gestational age, birth weight, and the severity of RDS in the multivariate regression analysis.
Therefore, we are unable to determine whether there is a significant association between the need for PDA treatment and these clinical characteristics.

\section{Conclusion}

Serial daily echocardiographic assessment can be useful in predicting whether a PDA will be closed with NSAIDs and/or surgical ligation in preterm infants with gestational age $\leq 30$ weeks.

Acknowledgements I would like to express my gratitude to all those who have helped me during the writing of this thesis. I gratefully acknowledge the help of Professor Shi Liping. I do appreciate her patience, encouragement, and professional instructions during my thesis writing.

Authors' Contributions TXL designed the study. He is also responsible for the assessment of echocardiography and data recording. TXL, Chen Z., and XLM were responsible for the data collection of demographic and clinical characteristics, statistics, and data interpretation. TXL wrote the first draft of the manuscript. All authors approved the final version of the manuscript.

Funding This study had no financial support.

Data Availability The datasets used or analyzed during the current study are available from the corresponding author on reasonable request.

Code Availability Not applicable.

\section{Declarations}

Conflict of interest The authors declare that they have no conflict of interest.

Ethical Approval All procedures performed in studies involving human participants were in accordance with the ethical standards of the institutional and/or national research committee and with the 1964 Helsinki declaration and its later amendments or comparable ethical standards.

Informed Consent Informed consent was obtained from all individual participants included in the study.

Consent for Publication Not applicable.

\section{References}

1. Hermes-DeSantis ER, Clyman RI (2006) Patent ductus arteriosus: pathophysiology and management. J Perinatol 26:S14-S18

2. Van Laere D, van Overmeire B, Gupta S, El-Khuffash A, Savoia M, McNamara PJ, Schwarz CE, de Boode WP, European Special Interest Group (2018) Neonatologist Performed Echocardiography' (NPE) Application of NPE in the assessment of a patent ductus arteriosus. Pediatr Res. 84(Suppl 1):46-56 
3. Majed B, Bateman DA, Uy N, Lin F (2019) Patent ductus arteriosus is associated with acute kidney injury in the preterm infant. Pediatr Nephrol 34(6):1129-1139

4. Su BH, Lin HY, Huang FK, Tsai ML, Huang YT (2016) Circulatory management focusing on preventing intraventricular hemorrhage and pulmonary hemorrhage in preterm infants. Pediatr Neonatol 57(6):453-462

5. Sellmer A, Bjerre JV, Schmidt MR et al (2013) Morbidity and mortality in preterm neonates with patent ductus arteriosus on day 3. Arch Dis Child Fetal Neonatal Ed. 98:F505-510

6. Hamrick SE, Hansmann G (2010) Patent ductus arteriosus of the preterm infant. Pediatrics 125:1020-1030

7. Noori S, McCoy M, Friedlich P, Bright B, Gottipati V, Seri I et al (2009) Failure of ductus arteriosus closure is associated with increased mortality in preterm infants. Pediatrics 123:e138-e144

8. Abdel-Hady H, Nasef N, Shabaan AE, Nour I (2013) Patent ductus arteriosus in preterm infants: do we have the right answers? Biomed Res Int 2013:676192

9. Noori S (2010) Patent ductus arteriosus in the preterm infant: to treat or not to treat? J Perinatol 30:S31-S37

10. Ognean ML, Boantă O, Kovacs S, Zgârcea C, Dumitra R, Olariu E, Andreicuţ D (2016) Persistent ductus arteriosus in critically ill preterm infants. J Crit Care Med (Targu Mures) 2(4):175-184

11. Evans N, Kluckow M (1996) Early ductal shunting and intraventricular haemorrhage in ventilated preterm infants. Arch Dis Child Fetal Neonatal Ed 75:F183-F186

12. McGrath RL, McGuinness GA, Way GL, Wolfe RR, Nora JJ, Simmons MA (1978) The silent ductus arteriosus. J Pediatr 93(1):110-113

13. Kluckow M, Evans N (1995) Early echocardiographic prediction of symptomatic patent ductus arteriosus in preterm infants undergoing mechanical ventilation. J Pediatr 127:774-779

14. Condò M, Evans N, Bellù R, Kluckow M (2012) Echocardiographic assessment of ductal significance: retrospective comparison of two methods. Arch Dis Child Fetal Neonatal Ed 97(1):F35-F38

15. Harling S, Hansen-Pupp I, Baigi A, Pesonen E (2011) Echocardiographic prediction of patent ductus arteriosus in need of therapeutic intervention. Acta Paediatr 100(2):231-235

16. de Freitas Martins F, Ibarra Rios D, Resende MH, Javed H, Weisz D, Jain A, de Andrade Lopes JM, McNamara PJ (2018) Relationship of patent ductus arteriosus size to echocardiographic markers of shunt volume. J Pediatr 202:50-55

17. Jain A, Shah PS (2015) Diagnosis, evaluation, and management of patent ductus arteriosus in preterm neonates. JAMA Pediatr 169(9):863-872
18. El Hajjar M, Vaksmann G, Rakza T, Kongolo G, Storme L (2005) Severity of the ductal shunt: a comparison of different markers. Arch Dis Child Fetal Neonatal Ed 90:F419-F422

19. Kwinta P, Rudziński A, Kruczek P, Kordon Z, Pietrzyk JJ (2009) Can early echocardiographic findings predict patent ductus arteriosus? Neonatology 95(2):141-148

20. Gillam-Krakauer M, Reese J (2018) Diagnosis and management of patent ductus arteriosus. NeoReviews 19(7):e394-e402

21. Parkerson S, Philip R, Talati A, Sathanandam S (2021) Management of patent ductus arteriosus in premature infants in 2020. Front Pediatr. 8:590578

22. Iyer P, Evans N (1994) Re-evaluation of the left atrial to aortic root ratio as a marker of patent ductus arteriosus. Arch Dis Child Fetal Neonatal Ed 70:F112-F117

23. Arlettaz R (2017) Echocardiographic evaluation of patent ductus arteriosus in preterm infants. Front Pediatr 21(5):147

24. Singh Y, Katheria A, Tissot C (2018) Functional echocardiography in the neonatal intensive care unit. Indian Pediatr 55(5):417-424

25. Walther FJ, Kim DH, Ebrahimi M, Siassi B (1989) Pulsed Doppler measurement of left ventricular output as early predictor of symptomatic patent ductus arteriosus in very preterm infants. Biol Neonate 56(3):121-128

26. El Hajjar M, Vaksmann G, Rakza T, Kongolo G, Storme L (2005) Severity of the ductal shunt: a comparison of different markers. Arch Dis Child Fetal Neonatal Ed 90(5):F419-F422

27. Engür D, Deveci M, Türkmen MK (2016) Early signs that predict later haemodynamically significant patent ductus arteriosus. Cardiol Young 26(3):439-445

28. Sehgal A, Menahem S (2013) Interparametric correlation between echocardiographic markers in preterm infants with patent ductus arteriosus. Pediatr Cardiol 34(5):1212-1217

29. Groves AM, Kuschel CA, Knight DB, Skinner JR (2008) Does retrograde diastolic flow in the descending aorta signify impaired systemic perfusion in preterm infants? Pediatr Res 63(1):89-94

Publisher's Note Springer Nature remains neutral with regard to jurisdictional claims in published maps and institutional affiliations. 